
\title{
R Reserach S Suare \\ Evaluation the toxic effects of Cobalt/Zinc/Ferrite nano-complex in experimental mice
}

\section{Eman E. El-Nahass}

Tanta University Faculty of Science

\section{Sabry A. El-Naggar}

Tanta University Faculty of Science

\section{Basant I. Salem}

Tanta University Faculty of Science

Mona M. elwan ( $\sim$ monaelwan287@yahoo.com )

Tanta University Faculty of Science

\section{Research Article}

Keywords: toxicity, Cobalt/Zinc/Ferrite, nanocomplex, mice, histopathology, liver, kidney

Posted Date: October 1st, 2021

DOI: https://doi.org/10.21203/rs.3.rs-941124/v1

License: (a) (i) This work is licensed under a Creative Commons Attribution 4.0 International License. Read Full License 


\section{Abstract}

Currently, nanoparticles (NPS) are in use in several applications especially in the biomedical field. The NPs showed promising results in the treatment of several diseases, however, NP S could have toxic effects on some vital organs. This study was conducted to evaluate the possible toxicity of Cobalt/Ferrite (CF NPs) and Cobalt/Zinc/Ferrite (CZF NPs) nano-complex. Eighty female mice were used to determine the median lethal dose (LD 50$)$ of CF NPs (100 mg/kg) and CZF NPs (100 mg/kg). Thirty female mice CD1 were divided into 3 groups ( $n=10)$ as follows: Group 1 (Gp1). Mice were injected with $200 \mu$ of sterile saline interperitoneal (i.p.). Gp2 and Gp3 were injected with CF NPs and CFZ NPs for 6 days. Hematological, biochemical, and histopathological parameters were determined at day 14 post injection. The results showed that there was a significant change in the total body weight in CZF NPs injected mice. CF NPs injections did not alter the values of the total red blood cells (RBCs), haemoglobin conc $(\mathrm{Hb})$, hematocrit Hct\%, total white blood cells (WBCs) and platelets while CZF NPs injections increased WBCs count and decrease the platelets count. Also, injection of CZF NPs altered the differential leukocyte percentages. There was no significant change in liver and kidney functions in CF NPs injected mice, while CZF NPs exhibited significant increases in liver and kidney bio-markers. The injection of mice with CF NP S didn't alters the histological architecture of hepatic and renal tissues, while the hepatic and renal structures were disorganized in CZF NPs injected mice. Collectively, the results revealed that CZF NPs showed a degree of toxicity on experimental mice.

\section{Introduction}

Nanomaterials (NMs) are tiny materials with dimensions ranged between 1 to $100 \mathrm{~nm}$, having electronic, optical and mechanical properties (Mech al. 2020). NMs have high impact on many fields of sciences including physics, engineering, biology, agriculture and food sciences due to its unique physicochemical properties (Szakal et al. 2014). NMs are broadly classified into three categories namely nanoparticles (NPs), nanoclays and nanoemulsions (Mageswari et al. 2016). Having this technology, multiple advantages to the delivery of natural compounds in the treatment of cancer and other human diseases (Patra et al. 2018). In particular, NPs were used to increase the delivery of nutrients into the cells (Acosta 2009).

Furthermore, NPs were used as targeted delivery system for drugs, proteins and genes (Zhang et al. 2000). Biologically active NPs included silver (Ag), gold (Au), titanium oxide, aluminum, cerium, zinc and silicon which possess great potential for wide applications in biomedical and clinical research settings including cancer therapy and diagnosis (Gendrikson et al. 2011). NPs have been found to induce cell death, detection of pathogens, enzyme immobilization and used in magnetic fluid hyperthermia application (Wang et al. 2007; Nikolova et al. 2020). Previous studies have been reported that Au, Ag NPs were used in cancer treatment (Jain et al. 2007; Erik et al. 2012). For instance, Au NPs have been used to treat skin cancer while Ag NPs have been used to treat breast and colon cancer (El-Deeb et al. 2015; Bromma and Chithrani 2020).

Another applications of NPs for instance, modern sunscreens contain insoluble non-toxic titanium dioxide (TiO2 NPs) or zinc oxide (ZnO NPs) which are efficient filters of UV light, offer large health benefits such as 
the protection of human skin against UV-induced skin ageing and cancer (Nohynek and Dufour 2012). There are two main routes of entry of the NPs into the human body. First, NPs are inhaled into the body from atmospheric air via the upper respiratory tract. Inhalation of metal NPs like Fe, Ni and TiO2NPs (SJeevanandam et al. 2018). The second way, oral ingestion and entry via the dermal route, either by injection into the dermal layer or absorption through the pores of the skin, are mainly mediated by exposure from therapeutic or cosmetic applications (Homayun et al. 2019).

NPs are useful for many applications, however, still have some health hazard in human health (Khalid et al. 2017). For instance, NPs may be harmful to normal tissues and cells and may cause serious consequences (Sukhanova et al. 2018). Biodegraded NPs may accumulate within cells and lead to intracellular changes such as disruption of organelle integrity or gene alterations (Ortega et al. 2009).

Previously, in vitro studies, Ag NPs showed highly toxic effect on liver cells with a significant decrease in mitochondrial function. The microscopic studies demonstrated that NPs -exposed cells at higher doses became abnormal in size, displaying cellular shrinkage and an acquisition of an irregular shape (Al-Qubaisi et al. 2011). It has been reported that inhaled NPs can reach the blood and may reach other target organs such as the liver and heart (Borm et al. 2006). Inhaled NPs can be deposited throughout the human respiratory tract and deposit in the lungs causing lung inflammation (Poh et al. 2018). It can potentially move from the lungs to other organs such as the brain, the spleen and possibly in to the foetus in pregnant women (Jia'en Li et al. 2010). NPs may cross the mucous membrane inside the nose and then reach the brain through the olfactory nerve (Sonvico 2018). Ag NPs produced hepatotoxicity as indicated by increased serum activity levels of both AST and ALT. Further, Ag NPs showed histological damages to the liver tissue, especially to hepatic lobules (Saeed et al. 2015). Cadmium sulphide nanoparticles (CdSNPs) induce increasing creatinine concentration in urine and extensive damage in proximal tubules causing nephrotoxicity (Rana et al. 2017). Au NPs cause DNA damage and inflammation leading to fibrosis and pneumoconiosis causing pulmonary toxicity (Jia'en Li et al. 2010). It has been reported that Ag NPs led to histological damge to liver and kidney (Nosrati et al. 2021). Previous study showed that silica nanoparticles induced cardiovascular cytotoxicity as well as oxidative stress and apoptosis (Duan et al. 2013). Furthermore, it has reported that silica NPs induced Spinal cord injury (SCI), neurotoxicity and neuroprotection (Sharma et al. 2009).

Cobalt NPs (Co NPs) exhibit mild anti-proliferative character against ovarian cancer cells and safe towards the normal cells. Also, it has reported that treatment with Co NPs did not alter the hematological parameters (Ansari et al. 2017). Fe, Cu, Cr, V, Zr NPs can cause the production of ROS that induced DNA and cellular damage in liver, kidney, muscle, brain and pancreas (Li et al. 2020).

Zinc oxide NPs (ZnO NPs) at high concentration lead to significant changes in liver enzymes, oxidative stress, liver and renal tissue and sperm quality and quantity (Abbasalipourkabir et al. 2015). ZnO NPs were accumulated and had toxic effects on the liver leading to destructive tissue and cellular changes, reduced the levels of serum triglyceride, glucose, cholesterol, albumin, and increased the bilirubin and liver enzymes, such as ALT, AST, ALP, amylase and lipase at high doses (Abbasalipourkabir et al. 2015). In addition, the evidence of histopathological lesions, hyperemia, inflammatory cell infiltration, and necrosis were noted in 
the liver and pancreas tissue slides upon microscopic examinations. Finally, the body and liver weights decreased in the rat groups receiving ZnO nanoparticle dose dependently (Hosseini et al. 2020).

ZnO NPs oral administration induced oxidative stress and destructive genotoxic effects in the stomach and pancreatic cells, it induced a significant decrease in serum glutathione and significant increase in serum MDA causing severe histopathological alterations in stomach and pancreatic cells with DNA fragmentation (Abdallah 2018).

There are few reports on Fe304 toxicity especially under in vivo conditions and moreover some researchers showed controversial results. For instance, some studies have reported minimal toxicity in some concentrations and some others have shown non-toxicity effects under in vivo conditions (Garcia et al. 2005; Kim et al. 2006). Others have reported damages and changes in liver, kidney, gastrointestinal and neuronal systems in vivo (Brooking et al. 2011; Arora et al. 2012; Amiri and Shokrollahi 2013). Therefore, this study was conducted to evaluate the toxic effects of the complex of Cobalt/Zinc/Ferrite nanoparticales on liver and kidney tissues.

\section{Materials And Methods}

\section{Chemicals}

Cobalt/Zinc/Ferrite complex of nanoparticles (CZF NPs) and Cobalt Ferrite nano-particles (CF NPs) were prepared in the Department of Physics, Faculty of Science, Tanta University. Serum alanine aminotransferase (ALT), serum aspartate aminotransferase (AST), creatinine and urea kits were purchased from Bio-diagnostic Company (Egypt).

\section{CZFNPs and CFNPs preparation}

Nanoparticales (NPs) were prepared using flash-combustion methods. In this technique, $\left(\mathrm{Co}\left(\mathrm{NO}_{3}\right)_{2} \cdot 6 \mathrm{H}_{2} \mathrm{O}\right)$, $\left(\mathrm{Fe}\left(\mathrm{NO}_{3}\right)_{3} \cdot 9 \mathrm{H}_{2} \mathrm{O}\right),\left(\mathrm{Zn}\left(\mathrm{NO}_{3}\right)_{2} \cdot 6 \mathrm{H}_{2} \mathrm{O}\right)$, and $\mathrm{CO}\left(\mathrm{NH}_{2}\right)_{2}$ were used. These chemicals were weighed in the required stoichiometric proportions and good mixed together for a few minutes and then heated at $80{ }^{\circ} \mathrm{C}$ on a hot plate. Thermal dehydration resulted in a highly viscous liquid. With more heating, the viscous liquid swelled and auto-ignited, to harvest voluminous powder. The reaction was very fast and dry very fine brown powder was obtained (Mansour et al. 2016).

\section{Experimental animals}

Female Swiss albino mice (20 $\pm 2 \mathrm{~g})$ were obtained from National Research Center (NRC, Cairo, Egypt). Animals were housed (6/cage), in $12 \mathrm{~h} / 12 \mathrm{~h}$ dark/light cycle under laboratory condition of temperature and humidity. Mice were kept for a week before starting the experiment for adaptation and then handled according to the ethical guidelines approved by the animal care and use committee, Faculty of Science, Tanta University (ACUC-SCI-TU), Egypt.

Determination of the medium lethal dose $\left(\mathrm{LD}_{50}\right)$ 
To determine $\mathrm{LD}_{50}$ of CZF NPs and CF NPs, eighty female mice were used. Briefly, different concentrations ranged from $1-5 \mathrm{~g} / \mathrm{kg}$ of CZF NPs and CF NPs were prepared and injected i.p. into different groups. Injected mice were monitored for $24 \mathrm{hrs}$ to observe any toxicological features to determine the $\mathrm{LD}_{50}$. $\mathrm{LD}_{50}$ was calculated by Probit analysis according to (Finney 1971).

\section{Experimental design}

Thirty female CD-1 mice were divided into three groups (10 mice /group) as follows: Group 1 (Gp1) was used as a negative control, injected with sterile saline $(10 \mathrm{~mL} / \mathrm{kg})$ i. p. for 6 days. Gp2 was injected with CF NPs (100 mg/kg/ 6days) i.p. and Gp3 was injected with CZF NPs (100 mg/kg/ 6 days) i.p. Post 14 days, all groups were bled via the orbital plexus to collect blood for hematological and biochemical assessments. Mice were weighted, and then sacrificed to harvest liver and kidney tissues for histological investigations.

\section{Determination of body weight change}

Mice from all groups under the study were weighed at the beginning (initial b.wt) and at the end of the experiments (final b.wt). The percentage of b.wt change \% was calculated as follows: The percentage of b.wt change $=[($ final b.wt - initial b.wt $) /$ initial b.wt $] \times 100$

\section{Hematological and biochemical analysis}

To determine the hematological parameters, the total count of red blood cells (R.B.Cs), haemoglobin ( $\mathrm{Hb}$ ) concentration $(\mathrm{g} / \mathrm{dL})$, haematocrit $(\mathrm{Hct})$ value $(\%)$, platelets count, as well as total and differential leucocyte counts were determined by using the auto hematology analyzer (BC-3200, Mindray, China). For biochemical analysis, blood samples were collected in heparinized glass tubes. Serum was separated from the blood samples by centrifugation at $3000 \mathrm{rpm}$ for $15 \mathrm{~min}$. ALT, AST were measured by commercial kits (Reitman and Frankel 1957). Serum creatinine and urea levels were determined by commercial kits.

\section{Histological investigations of liver and kidney tissues}

Tissue sections of the liver and kidney were immediately collected after sacrificing animals under an appropriate anesthesia then were sliced small pieces and fixed in 10\% formalin for 24 hours. After washing to remove the excess of fixative, the tissue samples were dehydrated in ascending serial ethanol and cleared by xylene. Tissue spices were embedded in paraffin wax. Sections of $5 \mu \mathrm{m}$ thickness were mounted and stained with haematoxylin and eosin for histological examination (Bancroft and Gamble 2008).

\section{Statistical analysis}

Data were presented as mean \pm SD and were analyzed using one-way analysis of variance (ANOVA) followed by Dunnet test and $p<0.05$ or $p<0.01$ were statistically significant.

\section{Results}

CF NPs and CZF NPs $L_{50}$ post 24 hrs. of I.P. injection 
Different doses of CF NPs and CZF NPs were prepared and used to detect the median lethal dose $\left(\mathrm{LD}_{50}\right)$ post-24 hr. of injection. The concentrations varied from 1 to $5 \mathrm{~g} / \mathrm{kg}$. The results showed that the $\mathrm{LD}_{50}$ of $\mathrm{CF}$ NPs and CZF NPs were 4.3 and $4.6 \mathrm{~g} / \mathrm{kg}$, respectively (Figure 1).

\section{CZF NPs injection decreased the percentage of body weight changes}

Group of mice that injected with CF NPs $\left(1 / 40 L_{50}\right)$ and CZF NPs $\left(1 / 40 L_{50}\right)$ for 6 days were noticed for body weight changes (b.wt\%). The data showed that CF NPs injected mice were similar in regard to \% of b.wt changes to the control group. While there was a significant change in the total body weight in CZF NPs injected mice when compared to their control (Figure 2). In Figure 2, the \% b.wt change in the group of mice which injected with CF NPs and CFZ NPs were 53.4 and 11.1 respectively.

\section{Injection of CZF NPs 6 days altered some hematological parameters}

As shown in table $1 \mathrm{~A}$, the results showed that injection of CF NPs did not alter the values of the total red blood cells (RBCs), haemoglobin conc $(\mathrm{Hb})$, hematocrit $\mathrm{Hct} \%$, total white blood cells (WBCs) and platelets when compared to their control values. However, CZF NPs injection daily for 6 days increased WBCs count and decrease the platelets count (Table 1A). The results showed that injection of CF NPs didn't alter the differential leukocyte percentages. However, injection of CZF NPs altered these percentages. The percentages of lymphocytes, neutrophils and monocytes were $51.3,29.7$, and $16.7 \%$ in the group of mice that injected with CZF NPs (Table 1B).

\section{CZF NPs injection led to hepatorenal dysfunction}

The results showed that injection the group of mice with CF NPs for 6 days didn't alter the liver transaminases enzymes (ALT and AST) and didn't change the levels of urea and creatinine when compared to their control group. Furthermore, the results showed that injection group of mice with CZF NPs did increase the ALT and AST activities, as well as increase the levels of urea and creatinine (Table 2).

\section{CZF NPs induced hepatic-architecture alterations}

Microscopic examination of liver sections of control group (Gp1) showed normal strands of hepatocytes had homogenous granular cytoplasm with centrally located nucleus. The liver strands were alternating with narrow blood sinusoids lined by endothelial cells and distinct phagocytic Kupffer cells (Fig. 3A). Treatment of the mice with CF NPs exhibited normal like structure of hepatic construction, normal central vein, irregular hepatic strands, hepatocytes with normal nuclei, other hapatocytes with megakaryocytic nuclei, and irregular blood sinusoids with distinct phagocytic Kupffer cells were seen (Fig.3B). While treatment of the mice with CZF NPs showed disorganization of the hepatic manner, irregular and congested central veins, some hepatocytes with pyknotic nuclei, others with vacuolated cytoplasm and widening blood sinusoids with distinct phagocytic Kupffer cells were noticed (Fig.3C).

\section{CZF NPs induced renal architecture alterations}


Microscopic examination of kidney sections of control group (Gp1) showed normal renal cortex, normal glomeruli and normal renal tubules (Fig. 4A). Kidney section of mice of CF NPs group exhibited normal glomeruli with regular Bowman's space, few numbers of renal tubules are distended and dilated, others are damaged, destroyed and their lining epithelial cells became undistinguished and their contents were intermixed with each other (Fig. 4B). While Kidney section of mice of CZF NPs group revealed disorganized glomeruli with irregular Bowman's space, mostly renal tubules were damaged and lost their characteristic appearance, others were occluded with hyaline casts and their nuclei are darkly stained (Pyknotic nuclei) (Fig. 4C) .

\section{Discussion}

Toxicity is a critical factor which should be considered during evaluating potential biomedical use of NPs in vivo applications. In this study, we aimed to evaluate the toxic effects of CF NPs and CZF NPs on liver and kidney tissues. In the present study, the median lethal concentration of CF NPs and CZF NPs that killed $50 \%$ of mice was determined and the value was reported as 4.3 and $4.6 \mathrm{~g} / \mathrm{kg}$, respectively. Balakrishnan et al. (2020) reported that the acute toxicity study of cobalt ferrite nano-complex gave $L_{50}$ of $\left(25 \times 10^{-9} \mathrm{M}\right.$ and $50 \times 10^{-9} \mathrm{M}$ ) at 25 and $72 \mathrm{~h}$, respectively. The results showed that CF NPs injected mice were similar in regard to $\%$ of b.wt changes to the normal control group. While there was a significant change in the total body weight in CZF NPs injected mice when compared to their control. This decrease in the \% b.wt after CZF NPs injection indicates that this complex could have a toxic effect on the body organs. This finding was in accordance with the previous study that showed \% b.wt changes was decreased upon the injection of mice with ZNO NPs (Novotna et al. 2016; Hosseini et al. 2020).

Mice injected with CF NPs didn't show any alteration in the values of RBCs, Hb, Hct, \% W.B.Cs and platelets when compared to their control values. These results were in dis-agreement with Ansari et al. (2017) who revealed that $(<5 \%)$ hemolysis signifying the compatibility of Co NPs with human RBCs. On the other hand, injection with CZF NPs causes a significant increase in the total W.B.Cs count and lymphocytes, neutrophils and monocyte \% but decrease in platelets count. Our results revealed that injection of CF NPs did not alter the different leukocytes percentages. However, injection of CZF NPs altered these percentages. The results also showed that the injection with CF NPs did not change the levels of AST and ALT in serum while there were significantly increase in CZF NPs injected mice when compared to their control group. These findings were in line with previous studies showed $\mathrm{ZnO}$ NPs at high concentration accumulated and had toxic effect on the liver leading to destructive tissue, cellular changes, and significant increase in liver enzymes (Abbasalipourkabir et al. (2015). In the current study, treatment with CF NPs didn't show any significant change in urea and creatinine levels when compared with normal control mice while these levels were significantly increased in the CZF NPs treated mice. These parameters are often regarded as reliable markers of renal damage (Noori et al. 2014). In addition, serum creatinine has been used to estimate glomerular function and its increasing is an indicator of renal failure (Nankivell 2001).

This work revealed a relation between haematological, biological and histological parameters. The histopathological alterations that found in the group of mice that injected with CZF NPs revealed marked 
disorganization of hepatic architecture as degeneration and necrosis of many hepatocytes, cytoplasmic vacuolation, pronounced nuclear changes include pyknotic nuclei, congestion of blood vessels and inflammatory cell infiltration. Similar results were recorded by (Almansour et al. 2017). While liver sections of mice injected with CF NPs showed normal like structure of hepatic architecture with appearance of slight changes in the hepatic tissue as congestion of blood vessels and widening of blood sinusoids. Also, our results revealed that mice treated with CF NPs showing normal renal cortex, normal glomeruli with regular Bowman's space and normal renal tubules. While the kidney of the mice injected with CZF NPs induced histological alterations in the kidney tissues showing destructed, shrunken and congested glomeruli with irregular Bowman's space, most of the renal tubules were damaged and lost their characteristic appearance as well as intertubular haemorrhage was observed, these findings were supported with those of Abdel-Aziz et al. (2018) who found that ZnO NPs causes histopathological changes of the kidney through oxidative stress.

In conclusion, the obtained results indicate that CZF NPs were toxic on liver and kidney tissues as estimated by increasing levels of AST, ALT, urea and creatinine at concentrations of $1 / 404.6 \mathrm{~g} / \mathrm{kg}$ which cause hepato-renal dysfunction, while CF NPs are non-toxic at concentrations of $1 / 404.3 \mathrm{~g} / \mathrm{kg}$.

\section{Declarations}

Conflict of interest the authors declare no competing interests.

\section{References}

Abbasalipourkabira R, Hemen M, Zareic S, Asadia S, Salehzadehd A, Ghafourikhosroshahie A, Mortazavif M, Ziamajidi N (2015) Toxicity of zinc oxide nanoparticles on adult male Wistar rats. Food and Chemical Toxicology 84: 154-160.

Abdallah EA (2018) A study of sub-chronic genotoxic effects of zinc oxide nanoparticles and protective role vitamin E on stomach and panrease in adult albino rats. Egypt J. Forensic Sci. Appli. Toxicol Volume 18, Issue 3: 25-41. DOI: 10.21608/EJFSAT.2018.4194.1017

Abdel-Aziz OH, Ragab EE, Hamdan MH (2018): The histological effects of zinc oxide nanoparticles on the kidney of adult male rabbits. Sohag Medical Journal Vol. 22 No. 2: 297-301

Acosta P (2009): Bioavailability of nanoparticles in nutrient and nutraceutical delivery. Journal of International Economics 79 (1): 102-116. DOI: 10.1016/j.cocis.2008.01.002

Almansour IM, Alferah AM, Shraideh AZ, Jarrar MB (2017) Zinc oxide nanoparticles hepatotoxicity: Histological and histochemical study. Environmental Toxicology and Pharmacology. 51: 124-130.

Al-Qubaisi M, Rozita R, Yeap SK, Omar AR, Ali AM, Alitheen NB (2011) Selective cytotoxicity of goniothalamin against hepatoblastoma HepG2 cells. Molecules 16(4): 2944-2959. 
Amiri S and Shokrollahi H (2013) The role of cobalt ferrite magnetic nanoparticles in medical science. Materials Science and Engineering 33: 1-8. https://doi.org/10.1016/j.msec.2012.09.003

Ansari SM., Bhor RD, Pai KR., Sen D, Mazumder S, Ghosh K, Kolekar YD, Ramana CV (2017) Cobalt nanoparticles for biomedical applications: facile synthesis, physiochemical characterization, cytotoxicity behavior and biocompatibility. Applied Surface Science 414: 171-187.

Arora S, Sharma P, Kumar S (2012) Gold-nanoparticle induced enhancement in growth and seed yield of Brassica juncea . Plant Growth Regul 66: 303-310. https://doi.org/10.1007/s10725-011-9649-z

Balakrishnan P, Bala S, Niccolò FC, Tamara (2020) Exploiting Unique Alignment of Cobalt Ferrite Nanoparticles, Mild Hyperthermia, and Controlled Intrinsic Cobalt Toxicity for Cancer Therapy. Advanced Materials. 32: 1-11, 2003712. ISSN 0935-9648 https://doi.org/10.1002/adma.202003712

Bancroft JD, Gamble M (2008) Theory and Practice of Histological Techniques. 6th ed. Churchill Livingstone/Elsevier, Philadelphia, PA, USA, pp. 725.

Borm P, Robbins D, Haubold S. Oberdorster E (2006): The potential risks of nanomaterials: A review carried out for ECETOC Part. Particle and Fibre Toxicology 3(1, article 11):11. DOI: 10.1186/1743-8977-3-11

Bromma K and Chithrani DB (2020) Advances in Gold Nanoparticle-Based Combined Cancer Therapy. Nanomaterials 10(9):1671. https://doi.org/10.3390/nano10091671

Duana J, Yua Y, Lib Y, Yua Y and Sunab Z (2013): Cardiovascular toxicity evaluation of silica nanoparticles in endothelial cells and zebrafish model. Biomaterials. 34 (23): 5853-

5862. https://doi.org/10.1016/j.biomaterials.2013.04.032

El-Deeb NM, El-Sherbiny IM, El-Aassar MR. and Hafez EE (2015): Novel Trend in Colon Cancer Therapy Using Silver Nanoparticles Synthesized by Honey Bee. Nanomedicine and Nanotechnology. 6: 265. doi:10.4172/2157-7439.1000265

Erik C, Dreaden A, Alaaldin M, Alkilany B, Xiaohua Huang C, Catherine J, Murphy D, El-Sayed MA (2012) The golden age: gold nanoparticles for biomedicine. Chem. Soc. Rev 41: 2740-2779. DOI:

10.1039/C1CS15237H

Finney D J (1971) Probit analysis. Cambridge [Eng.]: University Press

Gendrikson OD, Safenkova I, Anatoly V, Vladimir Z, Popov $O$ (2011): Methods of detection and identification of manufactured nanoparticles. Biofizika 56(6):965-94.

Homayun B, Lin X, Choi HJ. (2019): Challenges and Recent Progress in Oral Drug Delivery Systems for Biopharmaceuticals. Pharmaceutics; 11(3):129. https://doi.org/10.3390/pharmaceutics11030129

Hosseini SM, Amani R, Moshrefi AH, Razavimehr SV, Aghajanikhah MH, Sokouti Z (2020) Chronic Zinc Oxide Nanoparticles Exposure Produces Hepatic and Pancreatic Impairment in Female Rats. Iranian 
Journal of Toxicology. 14(3):145-154. http://dx.doi.org/10.32598/ijt.14.3.626.1:

http://dx.doi.org/10.32598/ijt.14.3.626.1

Jain KK (2007) Nanobiotechnology-Based Drug Delivery to the Central Nervous System. Neurodegenerative Dis 4:287-291. https://doi.org/10.1159/000101884

Jeevanandam J, Barhoum, CY, Dufresne A, Danquah MK (2018) Review on nanoparticles and nanostructured materials: history, sources, toxicity and regulations. Beilstein J. Nanotechnol. 9: 10501074. doi:10.3762/bjnano.9.98

Jia'en Li J, Muralikrishnan S, Teng Ng C, Lanry Yung LY, Bay BH (2010) Nanoparticle-induced pulmonary toxicity. Experimental Biology and Medicine 235 (9). https://doi.org/10.1258/ebm.2010.010021

Khalid IK, Khan SI (2017) Nanoparticles: Properties, applications and toxicities. Arabian Journal of Chemistry. 12 (7): 908-931.

Kim D, Jeong S, Moon J (2006) Synthesis of silver nanoparticles using the polyol process and the influence of precursor injection. Nanotechnology $17: 4019-4024$.

Li S, Li H, Xu X, Saw PE, Zhang L (2020) Nanocarrier-mediated antioxidant delivery for liver diseases. Theranostics 10(3):1262-1280. doi:10.7150/thno.38834. Available from https://www.thno.org/v10p1262.htm

Mageswari A, Srinivasan R, Subramanian P, Ramesh N, Gothandam KM (2016) Nanomaterials: Classification, Biological Synthesis and Characterization. In book. Nanoscience in Food and Agriculture 3. DOI: 10.1007/978-3-319-48009-1_2

Mansour SF, Hemeda OM, El-Dek SI, Salem BI (2016) Magn. Mater. Magn J 420: 7-18.

Mech A, Wohlleben W, Ghanem A, Hodoroaba VD., Weigel S, Babick F, Raphael Brüngel R, Friedrich CM, Rasmussen K, Rauscher H (2020) Nano or Not Nano? A Structured Approach for Identifying Nanomaterials According to the European Commission's Definition. Small 16, 2002228 https://doi.org/10.1002/smll.202002228

Nankivell JB (2001) Creatinine clearance and the assessment of renal function. Australian Prescriber 24. (1): 15-17.

Nikolova MP, Chavali MS (2020) Metal Oxide Nanoparticles as Biomedical Materials. Biomimetics 5(2): 27. https://doi.org/10.3390/biomimetics5020027

Nohynek GJ, Dufour E (2012): Nano-sized cosmetic formulations or solid nanoparticles in sunscreens: A risk to human health? Archives of Toxicology 86(7):1063-75. DOI: 10.1007/s00204-012-0831-5

Noori1 A, Karimi F, Fatahian S, Yazdani F (2014) Effects of zinc oxide nanoparticles on renal function in mice. International Journal of Biosciences 5 (9): 140-146. 
Nosrati H, Hamzepoor M, Sohrabi M, Saidijam M, Assari MJ, Shabab N, Mahmoudian ZG, Alizadeh Z (2021) The potential renal toxicity of silver nanoparticles after repeated oral exposure and its underlying mechanisms. BMC Nephrology 22:228 https://doi.org/10.1186/s12882-021-02428-5

Novotna B, Turnovcova K, Veverka P, Jr RP, Bagryantseva Y, Herynek V, Zvatora P, Vosmanska M, Klementova $M$, Sykova $E$, Jendelova $P(2016)$ The impact of silica encapsulated cobalt zinc ferrite nanoparticles on DNA, lipids and proteins of rat bone marrow mesenchymal stem cells. Nanotoxicology. 10: 662-670. https://doi.org/10.3109/17435390.2015.1107144

Ortega R, Devès G, Carmona A (2009): Biometal imaging and speciation in cells using proton and synchrotron radiation X-ray microscopy. J. R. Soc. Interface 6, S649-S658

Patra JK, Das G, Fraceto LF, Campos EVR, Rodriguez-Torres MP, Acosta-Torres LS, Diaz-Torres LA, Grillo R, Swamy M. K., Sharma, Habtemariam S, Shin. HS (2018) Nano based drug delivery systems: recent developments and future prospects. Journal of Nanobiotechnology. volume 16(71):16-

71. https://doi.org/10.1186/s12951-018-0392-8

Poh TY, Binte NA, Ali M, Aogáin MM, Kathawala MH, Setyawati Ml, Ng KW, Chotirmall SH (2018) Inhaled nanomaterials and the respiratory microbiome: clinical, immunological and toxicological perspectives. Particle and Fibre Toxicology. 15 (46).

Rana K, Verma Y, Rana RS (2018) Renal toxicity of nanoparticles of cadmium sulphide in rat. Chemosphere 193: 142-150. DOI: 10.1016/j.chemosphere.2017.11.011

Reitman S, Frankel S (1957) A colorimetric method for the determination of serum glutamic oxalacetic and glutamic pyruvic transaminases. Am J Clin Pathol 28(1):56-63.

Saeed M, Roya H, Samani J, Aghaeivanda S (2015) Toxic Effects of Silver Nanoparticles on Liver and Some Hematological Parameters in Male and Female Mice (Mus musculus). Biological Trace Element Research 165(2). DOI: 10.1007/s12011-015-0247-1

Sharma HS, Ali SF, Hussain SM, Schlager JJ, Sharma A (2009) Influence of engineered nanoparticles from metals on the blood-brain barrier permeability, cerebral blood flow, brain edema and neurotoxicity. An experimental study in the rat and mice using biochemical and morphological approaches. J Nanosci Nanotechnol 9(8):5055-5072

Sonvico (2018) Surface-Modified Nanocarriers for Nose-to-Brain Delivery. Pharmaceutics. 10(1):34. doi: 10.3390/pharmaceutics10010034.

Szakal C, Roberts SM, Westerhoff P, Andrew B, Buck N, Illuminato I, Canady R, Rogers M (2014) Measurement of Nanomaterials in Foods: Integrative Consideration of Challenges and Future Prospects. ACS Nano, 8 (4): 3128-3135 DOI: 10.1021/nn501108g. 
Wang MD, Shin DM, Simons JW, Nie S (2007): Nanotechnology for targeted cancer therapy. Expert Rev Anticancer Ther 7(6):833-837.

Zhang F, Kitamoto Y, Abe M, Naoe M (2000) Effect of Ni addition into Co ferrite thin films for perpendicular recording media. Journal of Applied Physics 87: 6881-6883.

\section{Tables}

Table 1A. The hematological parameters of mice treated with CF NPs or CFZ NPs for 6 days

\begin{tabular}{|c|c|c|c|c|c|}
\hline Groups & R.B.Cs $\left(\times 10^{6} / \mu \mathrm{L}\right)$ & $\mathrm{Hb}(\mathrm{g} / \mathrm{dL})$ & Hct (\%) & W.B.Cs $\left(\times 10^{3} / \mu L\right)$ & Platelets $\left(\times 10^{3} / \mu \mathrm{L}\right)$ \\
\hline Control & $6.67 \pm 1.7^{\mathrm{a}}$ & $12.97 \pm 0.9 \mathrm{a}$ & $39.2 \pm 2.5^{\mathrm{a}}$ & $7.43 \pm 1.4 \mathrm{~b}$ & $968.88 \pm 76.7^{\mathrm{a}}$ \\
\hline CF NPs & $7.9 \pm 0.6^{a}$ & $12.4 \pm 0.8^{a}$ & $37.6 \pm 1^{a}$ & $8.8 \pm 2.9^{b}$ & $881.7 \pm 198.6^{a}$ \\
\hline CFZ NPs & $8.5 \pm 0.5^{a}$ & $13.1 \pm 1.6^{\mathrm{a}}$ & $38.2 \pm 4.9^{a}$ & $16.3 \pm 3.9^{a}$ & $795 \pm 113^{b}$ \\
\hline
\end{tabular}

The values represented mean \pm SD. CF NPs: Cobalt Ferrite Nanoparticles, CFZ NPs: Cobalt Ferrite Zinc Nanoparticles

Table 1B. Absolute numbers of the differential leucocytes in different groups under the study

\begin{tabular}{|c|c|c|c|}
\hline Groups & \multicolumn{2}{|c|}{ Total number of different leukocytes $\left(\times 10^{3 /} \mu \mathrm{L}\right)$} \\
\hline & Monocytes $\left(\times 10^{3 /} \mu \mathrm{L}\right)$ & Lymphocytes $\left(\times 10^{3 /} \mu \mathrm{L}\right)$ & Neutrophils $\left(\times 10^{3 /} \mu \mathrm{L}\right)$ \\
\hline Control & $2.67 \pm 0.58^{\mathrm{b}}$ & $80.33 \pm 6.51^{\mathrm{a}}$ & $17.0 \pm 5^{\mathrm{a}}$ \\
\hline CF NPs & $13.3 \pm 9.5^{\mathrm{a}}$ & $71 \pm 13^{\mathrm{a}}$ & $15.7 \pm 3.5^{\mathrm{c}}$ \\
\hline CFZ NPs & $16.7 \pm 4.8^{\mathrm{a}}$ & $51.3 \pm 36.5^{\mathrm{b}}$ & $29.7 \pm 47.1^{\mathrm{b}}$ \\
\hline
\end{tabular}

The values represented mean \pm SD. CF NPs: Cobalt Ferrite Nanoparticles, CFZ NPs: Cobalt Ferrite Zinc Nanoparticles

Table 2. AST, ALT, urea and creatinine levels in different groups of mice treated with CF NPs or CFZ NPs

\begin{tabular}{|c|c|c|c|c|}
\hline Groups & AST (U/l) & ALT (U/l) & Urea (mg/dl) & Creatinine (mg/dl) \\
\hline Control & $173 \pm 8.9^{\mathrm{b}}$ & $48 \pm 3.5^{\mathrm{a}}$ & $35 \pm 3.2^{\mathrm{a}}$ & $0.38 \pm 0.05^{\mathrm{a}}$ \\
\hline CF NPs & $180 \pm 13.9^{\mathrm{a}}$ & $47 \pm 3.6^{\mathrm{a}}$ & $35.7 \pm 14.6^{\mathrm{a}}$ & $0.4 \pm 0.06^{\mathrm{a}}$ \\
\hline CFZ NPs & $217 \pm 19.7^{\mathrm{b}}$ & $59.7 \pm 9.9^{\mathrm{b}}$ & $48 \pm 11.1^{\mathrm{b}}$ & $0.47 \pm 0.05^{\mathrm{b}}$ \\
\hline
\end{tabular}

The values represented mean \pm SD. CF NPs: Cobalt Ferrite Nanoparticles, CFZ NPs: Cobalt Ferrite Zinc Nanoparticles

\section{Figures}



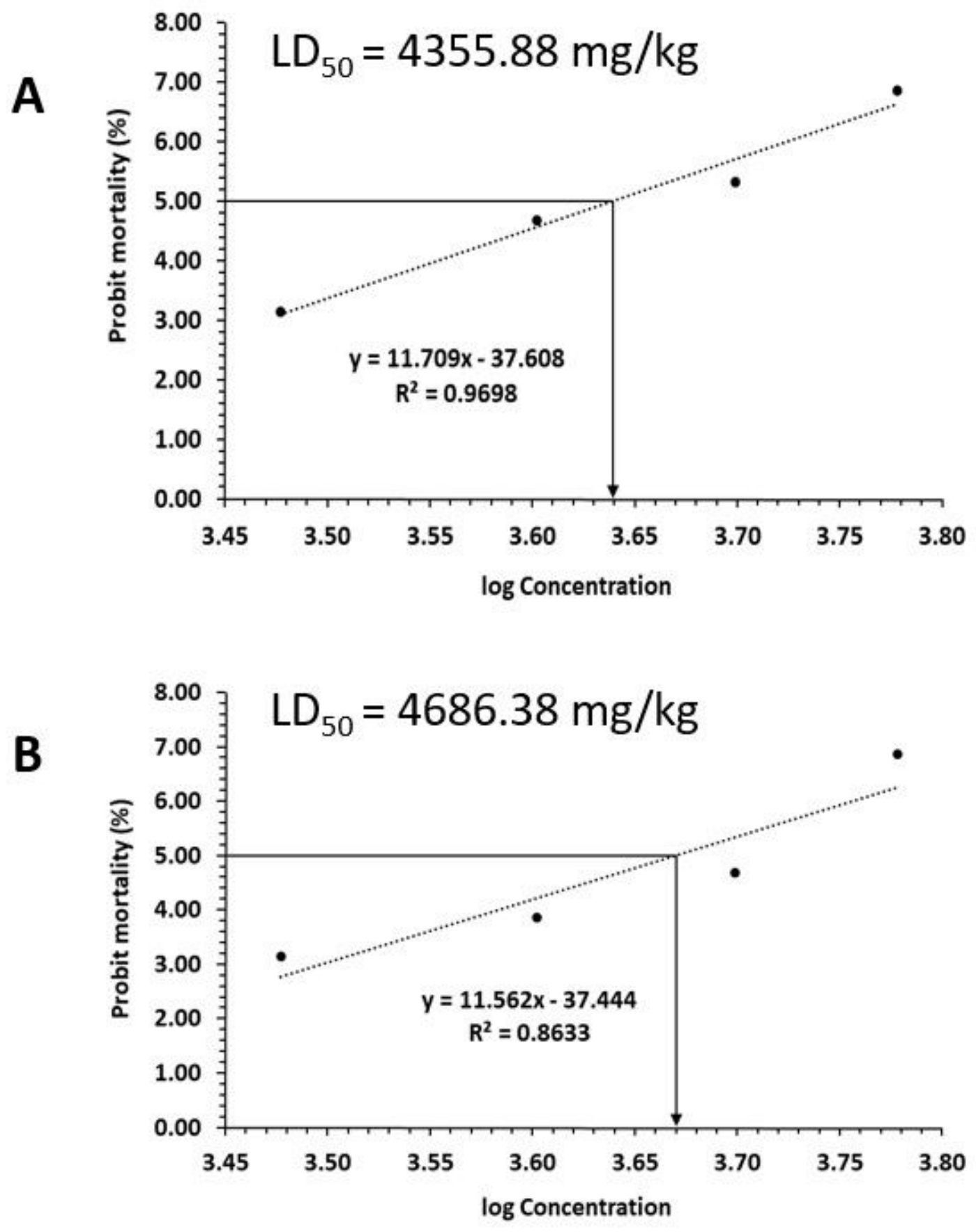

Figure 1

$(A, B)$ : Determination of LD50 of CF NPs and CZF NPs on albino Swiss mice 


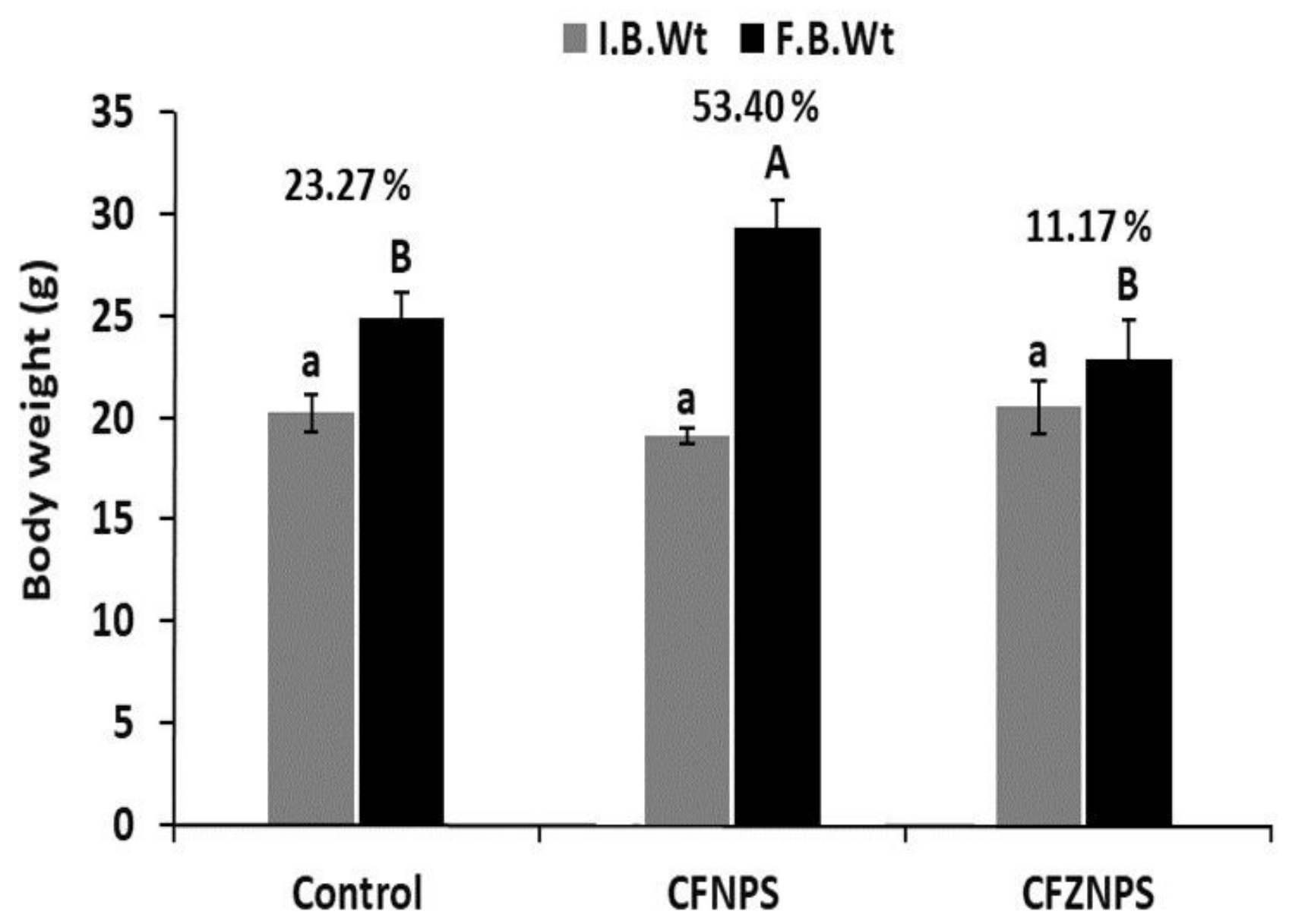

Figure 2

Initial and final weight of different groups under the study
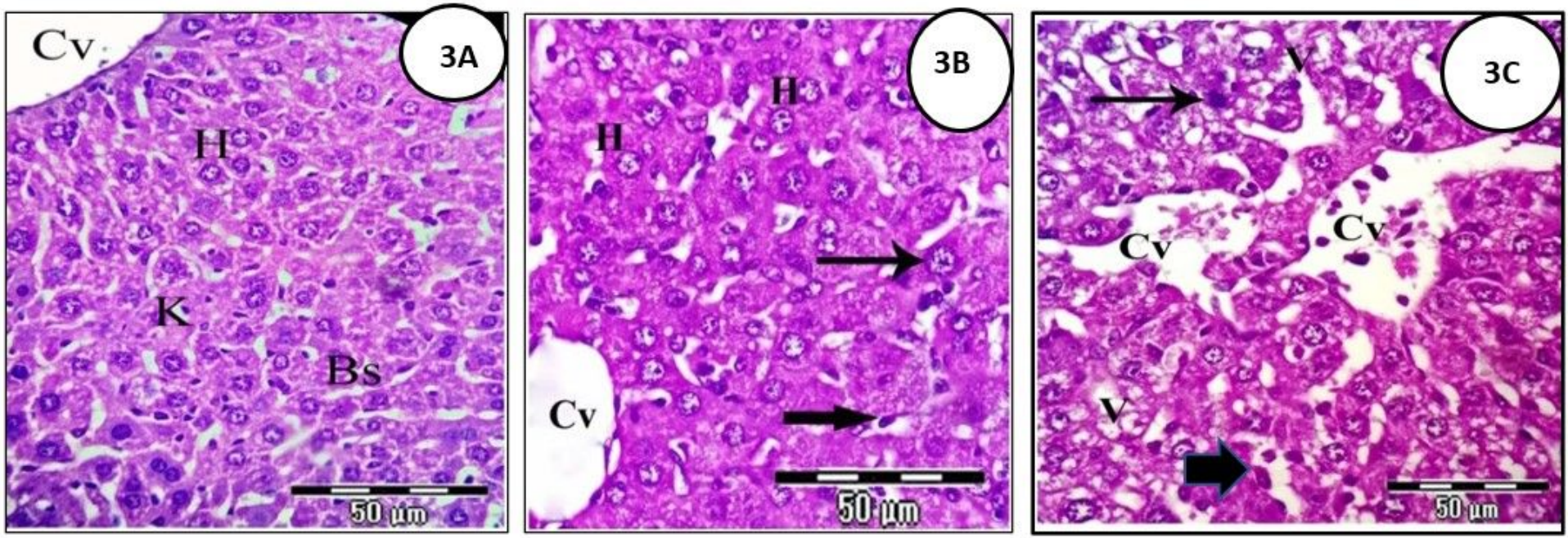

Figure 3 
(A-C). Photomicrographs of liver sections stained with H\&E showing. (A) Liver sections of control mice exhibit normal hepatic architecture, normal central vein (Cv), normal hepatic strands $(H)$, and regular blood sinusoids (Bs) lined with normal phagocytic Kupffer cells (K). (B) Liver sections of mice of CF NPs group showing normal like structure of hepatic construction, normal central vein (Cv), irregular hepatic strands $(H)$ with normal nuclei have regular distribution of chromatin, other hapatocytes with megakaryocytic nuclei (arrows), and irregular blood sinusoids with distinct phagocytic Kupffer cells (thick arrow). (C) Liver sections of mice of CZF NPs group exhibit disorganization of hepatic manner, irregular and congested central veins (Cvs), some hepatocytes with pyknotic nuclei (arrows), others with vacuolated cytoplasm (V) and widening blood sinusoids with distinct phagocytic Kupffer cells (thick arrow) were noticed (X400).
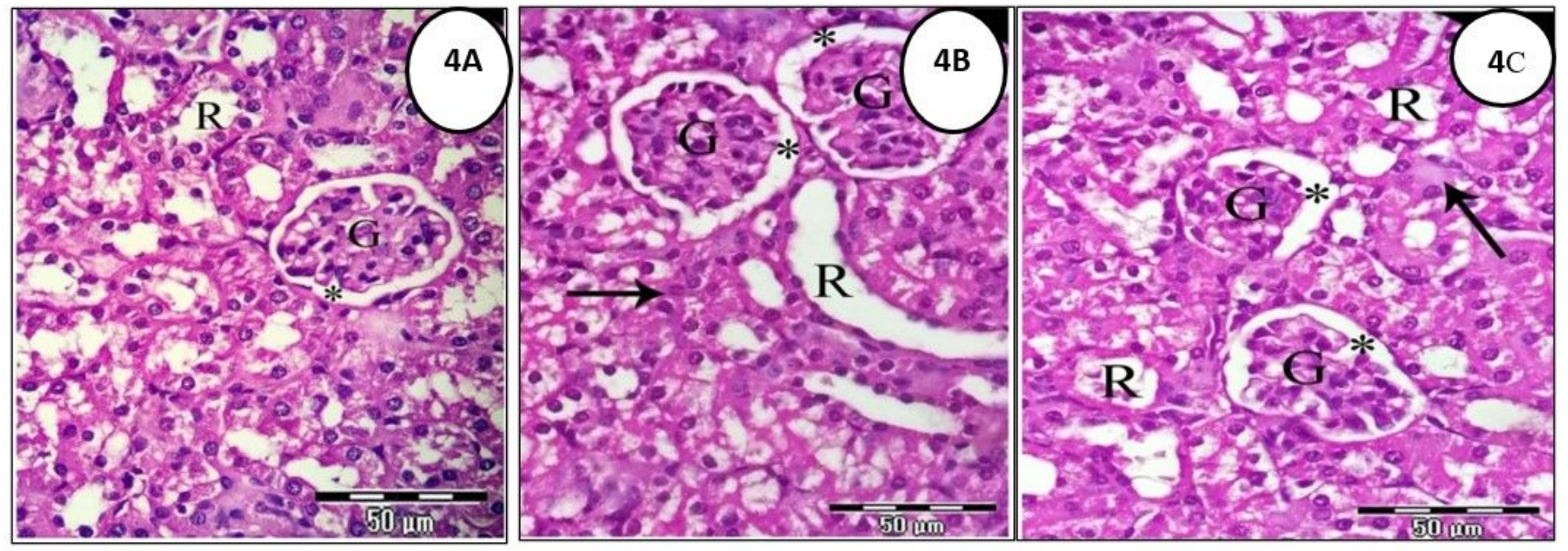

Figure 4

(A-C). Photomicrographs of kidney sections stained with H\&E showing. (A) Kidney section of control mice showed normal renal cortex, normal glomeruli $(G)$ and normal renal tubules $(R)$. (B) Kidney section of mice of CF NPs group exhibited normal glomeruli $(G)$ with regular Bowman's space $(*)$, few number of renal tubules are distended and dilated (R), others are damaged and destroyed (arrow), and their lining epithelial cells became undistinguished and their contents were intermixed with each other. (C) Kidney section of mice of CZF NP group showed that disorganized glomeruli $(\mathrm{G})$ with irregular Bowman's space $\left(^{*}\right)$, mostly renal tubules were damaged and lost their characteristic appearance $(R)$, others were occluded with hyaline casts (arrows) (X400). 